\title{
Placenta praevia with or without antepartum bleeding in a Nigerian suburban tertiary health institution
}

\author{
Olugbenga EO, Eifediyi RA*, Olugbenga MA, Ikheloa J, Okoeguale J, Omoregbee HI and \\ Oboh SA
}

Department of Obstetrics and Gynaecology, Irrua Specialist Teaching Hospital, Irrua, Edo State, Nigeria.

Accepted 25 April, 2019

\begin{abstract}
Placenta praevia is an abnormal implantation of the placenta in the lower uterine segment and it is a significant contributor to obstetric haemorrhage worldwide. This study was done to review the presentation, management modalities as well as obstetric outcome of placenta praevia with or without vaginal bleeding. This was a retrospective analysis of 125 cases of placenta praevia between $1^{\text {st }}$ January, 2011 and $31^{\text {st }}$ December, 2015. Information retrieved from case notes include the age, booking status, parity, level of education, gestational age at diagnosis, gestational age at delivery, symptoms at presentation, diagnosis, mode of delivery, past reproductive performance, blood transfusion as well as fetal and maternal outcomes. There were 8,735 deliveries in the period under review of which 125 patients had placenta praevia. This gave a prevalence of $1.4 \%$ or 14 cases per 1,000 deliveries. The mean age of occurrence was $30.9 \pm 2.107$ years. Majority of the patients were primipara with previous uterine surgeries (uterine evacuation, Caesarean section or myomectomy) and presenting mainly in unbooked patients (67.2\%). Diagnosis was made at term in $38.4 \%$ of the patients and $60.8 \%$ of the patients had warning bleeding or incidental ultrasound finding of placenta praevia before term. The commonest type of placenta praevia was type III $(48.8 \%)$ while the least common was type I (7.2\%). The delivery was by Caesarean section in $98.4 \%$ of the patients with $71.2 \%$ having emergency Caesarean section. Out of a total of 130 babies born to these patients, $109(83.8 \%)$ were live births. Seventy-seven women $(61.6 \%)$ of the studied population had blood transfusion out of which $60(78 \%)$ had at least 2 pints of blood transfused. There was no maternal mortality. In conclusion, the no maternal mortality recorded in this study could be attributed to the presence of highly skilled birth attendants, prompt surgical intervention and readily availability of blood transfusion services. Attendance of antenatal clinic and third trimester ultrasonography will reduce high rate of emergency delivery and better survival of babies.
\end{abstract}

Keywords: Placenta praevia, haemorrhage, blood transfusion and outcome.

${ }^{*}$ Corresponding author. E-mail: agbonsreuben@yahoo.com.

\section{INTRODUCTION}

Placenta praevia is an obstetric complication and classically defined as painless vaginal bleeding during the second or third trimester secondary to an abnormal placentation near or covering the internal cervical os (Calleja-Aguis et al., 2006; Tower, 2011; Nelson, 1995; Jennifer and Uzelac, 2007; Omu, 2004; Cunningham et al., 2001).

The incidence varies from one institution to another with a general variation from 0.2 to $1.8 \%$ of all deliveries
(Tower, 2011; Nelson, 1995; Jennifer and Uzelac, 2007; Omu, 2004; Cunningham et al., 2001; Kwawukume, 2002; Nyago et al., 2010; Ikechebelu and Onwusulu, 2007; Cieminski and Dlugolecki, 2005; Kiay, 2003; Bhat et al., 2004; Rosenberg et al., 2011; Sheiner et al., 2001; Ananth et al., 2001; Ananth et al., 2003; Loto and Onile, 2008). It contributes significantly to obstetric haemorrhage which is the leading cause of maternal mortality especially in developing countries (Calleja-Aguis 
et al., 2006), where the predisposing factors include high parity, advancing age, conditions with large placenta area such as multiple pregnancy, previous uterine surgeries like caesarean section, myomectomy, and hysterotomy, smoking, previous uterine instrumentation for induced abortions, infertility treatment and abnormal forms of placentation such as succenturate lobe (Tower, 2011; Nelson, 1995; Jennifer and Uzelac, 2007; Omu, 2004; Cunningham et al., 2001; Nyago et al., 2010; Ikechebelu and Onwusulu, 2007; Cieminski and Dlugolecki, 2005; Bhat et al., 2004; Rosenberg et al., 2011; Sheiner et al., 2001; Loto and Onile, 2008; Eniola et al., 2002; GurolUganzi et al., 2011).

Previous uterine surgery(ies) appeared to be the most prominent association as earlier confirmed by Rose and Chapman in 1986 and women with previous uterine scars are at increased risk of having morbidly adherent placenta which includes accreta or percreta (Tower, 2011).

A study from Eastern Europe shows a two to three fold increase in the incidence of Placenta praevia subsequent to liberalization of abortion law in 1960s. The suggested mechanism is that scarring of the endometrium from vigorous uterine curettage may lead to an abnormal site of placental implantation in subsequent pregnancies due to failure of differential growth of the lower segment of the uterus (Clarke et al., 1985).

In humans, the blastocyst is completely embedded in the substance of the endometrium so abnormalities of endometrial vascularization, delayed ovulation and prior trauma to the endometrium/myometrium appear to influence the site of implantation, therefore contributing to the probability of placenta praevia (Lavery, 1990).

The classification of placenta praeviais based on location of the placenta in the lower uterine segment. ${ }^{5}$ In marginal placenta praevia, the placenta is near the edge of the cervix but does not reach as far as the cervical os (also called type I) (Nelson, 1995; Omu, 2004). In partial placenta praevia, the placenta partially covers the cervix, this represents both type II and type III (Omu, 2004; Bendetti, 2002). In total placenta praevia also called type IV placenta praevia, or placenta centralis, the placenta totally covers the cervix (Omu, 2004; Bendetti, 2002).

The diagnosis of placenta praevia is aided by the history, clinical findings and investigations. The patient often presents with painless vaginal bleeding (CallejaAguis et al., 2006; Tower, 2011; Nelson, 1995; Jennifer and Uzelac, 2007; Omu, 2004; Cunningham et al., 2001; Hanretty, 2003). Some patients might have experienced spotting during the first and second trimesters (Nelson, 1995; Jennifer and Uzelac, 2007), it may however be asymptomatic with diagnosis being an incidental finding following routine obstetric ultrasound scan (Omu, 2004).

The uterus is usually soft, relaxed and non-tender while the presenting part is high with a high likelihood of abnormal presentation (Nelson, 1995; Omu, 2004).

Trans-abdominal ultrasonography can identify up to
95\% of placenta praevia (Jennifer and Uzelac, 2007). Trans-vaginal ultrasonography is recommended as a confirmatory method of placenta praevia suspected at trans-abdominal ultrasound scanning in mid-pregnancy (Nelson, 1995). Magnetic resonance imaging could also be used but it is very expensive (Nelson, 1995). The differential diagnosis of placenta praevia includes placenta abruptio or circumvalate placenta (Jennifer and Uzelac, 2007).

The management of placenta praevia depends on the amount of uterine bleeding, the duration of pregnancy and viability of the fetus; and whether or not labour has begun (Jennifer and Uzelac, 2007; Bendetti, 2002). Expectant therapy is indicated if initial haemorrhage is slight and it occurs before fetal pulmonary maternal and fetal pulmonary maturity (Jennifer and Uzelac, 2007; Omu, 2004). Maternal and fetal condition must also be stable (Jennifer and Uzelac, 2007; Omu, 2004), and the woman must not be in labour (Jennifer and Uzelac, 2007; Omu, 2004). Such expectant management has been found to improve both maternal and neonateal outcome (Jennifer and Uzelac, 2007; MacAfee, 1945). In such instances, the patient is hospitalized, anaemia is corrected and blood is made ready at all time (Omu, 2004), in case of need for emergency delivery. Dexamethasone or betamethasone to aid lung maturity may also be considered (Jennifer and Uzelac, 2007; Omu, 2004), while close ultrasonic monitoring is also indicated (Nelson, 1995; Omu, 2004). However, if there is massive haemorrhage, immediate resuscitation with blood is mandatory (Nelson, 1995; Omu, 2004) and Caesarean section is carried out promptly irrespective of the maturity of the fetus if the baby is to be salvaged (Nelson, 1995). It is also safer for the mother (Nelson, 1995).

There are complications that are associated with placenta praevia both to the fetus and mother. Preterm delivery is more common among woman with placenta praevia (Ananth et al., 2001). Antepartum bleeding before 32 to 34 weeks is a strong predictor for preterm birth and emergency delivery (Fishman et al., 2011; Fishman and Chasnen, 2011).

Neonatal anaemia is also a possible complication. In addition, neonatal mortality rate is higher with placenta praevia than among other pregnancies without praevia (Ananth et al., 2003). The risk of low birth weight is increased slightly among woman with praevia, chiefly due to preterm delivery and to a lesser extent fetal growth restriction (Ananth et al., 2001). Other complications from placenta praevia include severe blood loss resulting in cardiovascular collapse and renal failure, increased risk of primary postpartum haemorrhage, recurrent placenta and risk of therapeutic hysterectomy (Omu, 2004) ${ }^{5}$ death may also result (Jennifer and Uzelac, 2007).

Placenta praevia contributes greatly to obstetric haemorrhage and its consequences. However, the mortality rate can be greatly reduced if ideal obstetric and 
newborn care is given (Jennifer and Uzelac, 2007).

Studies carried out on the prevalence as well as fetomaternal outcome of placenta praevia were done in industrialized areas and a true picture of the same cannot be implied in a rural centre hence this study.

The main goal of this study is to determine the current prevalence, pattern of clinical presentation and type of placenta praevia, treatment modalities as well as maternal and neonatal outcome of placenta praevia in a Nigerian suburban population with specific objectives to determine the sociodemographic characteristics of patients with placenta praevia, prevalence of placenta praevia in ISTH and the pattern of presentation of placenta praevia

\section{MATERIALS AND METHODS}

This was a retrospective analysis of cases of placenta praevia with or without antepartum bleeding seen over a five year period (January $1^{\text {st }} 2011$ and December $31^{\text {st }} 2015$ ); at a tertiary health facility in Edo central senatorial district in Edo State, south-south, Nigeria. Subjects were all women with placenta praevia delivered between $1^{\text {st }}$ January 2011 and $31^{\text {st }}$ December 2015.

Permission was obtained from the ethics research committee of the hospital to embark on the study. The names of all patients were obtained from the antenatal ward, emergency unit, labour ward and the theatre records. The clinical case records of all these patients were retrieved from the case records department and cases of placenta praevia were selected from the poll. Information obtained from these records include patients age, parity, booking status, past obstetric performance, symptoms as well as maternal and fetal outcome indices. The data obtained were fed into Microsoft excel and analysed using descriptive statistics, percentages and tables.

\section{RESULTS}

A total number of 125 cases of placenta praevia were managed during the study period $\left(1^{\text {st }}\right.$ January, 2011 to $31^{\text {st }}$ December, 2015). There were a total of 8,735 deliveries thus giving the prevalence of placenta praevia of $1.4 \%$.

In Table 1, the mean age of the women with placenta praevia during the study was $30.9 \pm 0.02$ years with an age range of $22-45$ years. In term of parity, $27.2 \%$ of the patients were para $1,17.6 \%$ were para $2,23.2 \%$ were para 3 , while $18.4 \%$ were para 4 and above. However, $13.6 \%$ of the patients were nulliparous. Most of the patients $84(67.2 \%)$ were unbooked and presented on referral from other centres to the hospital. More than $60 \%$ of the patients had at least secondary level of education while $8 \%$ had no formal education. The level of education of $11.2 \%$ of patients was not documented.

Table 2 shows that majority of the patients 115 (92\%) presented with symptoms (bleeding) and 10(8\%) were asymptomatic (discovered on routine ultrasound scan). Fifty $(40 \%)$ patients had previous uterine evacuation, $7(5.6 \%)$ had previous Caesarean section, while one had a myomectomy scar $(0.8 \%)$. Type III placenta constituted
$48.8 \%$ of the cases while type I was the least with only $7.2 \%$ of cases.

Table 3 shows the relationship between gestational age and placenta praevia. The diagnosis was at term in $38.4 \%$ of cases while delivery was at term in $45.6 \%$. The mean gestational age at diagnosis was 35.6 weeks while the mean gestational age at delivery was 36.6 weeks. More than half $(52.8 \%)$ of the cases were delivered premature.

As shown in Table 4, in majority of the cases (48\%), no additional procedures apart from simple closure of the uterus to control haemorrhage, the main additional surgical procedure done was the application of stitches to the placenta bed in $28 \%$ of cases and peripartum subtotal hysterectomy in $9.6 \%$ of cases. An additional $6.4 \%$ of the women had sub-total hysterectomy after uterine artery ligation was done and in $5.6 \%$ of cases uterine artery ligation sufficed without the need for hysterectomy while in $2.4 \%$ of cases other procedures such as intrauterine catheterization was done.

Table 5 shows there were five cases of twin gestation with placenta praevia during the study period constituting $4 \%$ of total cases of placenta praevia. Two of the patients delivered vaginally while been prepared for Caesarean delivery.

Majority of the patients were discharged within 5 to 7 days on admission (57.6\%) while only two patients stayed more than 10 days on admission.

We also found that 77 patients $(61.6 \%)$ received blood transfusion with the majority (78\% of those transfused) receiving up to 2 or more units of blood.

\section{DISCUSSION}

In this study, the prevalence of placenta praevia was $1.4 \%$ or 14 cases per 1,000 deliveries. This was comparable to an incidence of $1.65 \%$ reported by Ikechbelu and Onwusulu (2007) and Loto and Onile (2008) which is at variance with an incidence of $0.5 \%$ by Ananth et al. (2001), $0.2 \%$ by Cieminski and Dlugolecki (2005), $0.6 \%$ by Bhat et al. (2004), $0.42 \%$ by Rosenberg et al. (2011) and $0.38 \%$ by Sheinar et al. (2001).

Most of the patients were in the age range of 35 to 39 years, confirming advanced maternal age as a risk factor. Similar finding was reported by Ciemniski and Dlugolecki (2005) and Bhat et al. (2004). The lowest incidence was found in the age group below 25 years of age.

In this study, $86.4 \%$ of the woman have had previous parous experiences while previous uterine evacuation was found in $40 \%$. This showed that multiparity and previous uterine evacuations are major risk factors associated with were associated with placenta praevia. Ikechebelu and Onwusulu (2007) reported that $50 \%$ of cases in their study were associated with previous uterine scar while Niyogo et al. (2010) found that previous uterine evacuation was found in $35.4 \%$ of cases and 
Table 1. Demography of the selected patients.

\begin{tabular}{lcc}
\hline Parameters & Number of patients $\mathbf{( n = 1 2 5 )}$ & Percentage \\
\hline Age & 0.0 & \\
$15-19$ & 20 & 0.0 \\
$20-24$ & 34 & 16.0 \\
$25-29$ & 30 & 27.2 \\
$30-34$ & 36 & 24.0 \\
$35-39$ & 4.0 & 28.8 \\
$40-44$ & 1.0 & 3.2 \\
$45-49$ & & 0.8 \\
& & \\
Parity & 17 & \\
0 & 34 & 13.6 \\
1 & 22 & 27.2 \\
2 & 29 & 17.6 \\
3 & 12 & 23.2 \\
4 & 10 & 9.6 \\
5 & 1.0 & 8.0 \\
6 & & 0.8 \\
Booking status & & \\
Booked & 41 & 32.8 \\
Unbooked & 84 & 67.2 \\
Level of education & & \\
None & & \\
Primary & 10 & 18.4 \\
Secondary & 23 & 20.8 \\
Tertiary & 52 & 11.2 \\
Not documented & 26 & \\
\hline
\end{tabular}

Caesarean section scar was found in $5.2 \%$ of cases which is comparable to $5.6 \%$ found in this study. Cieminski and Dlugolecki (2005), Bhat et al. (2004), Rosenberg et al. (2011) and Eniola et al. (2002) found multiparity as a strong risk factor in their separate studies.

In this study, antepartum haemorrhage was the presenting complaint in $92 \%$. This is similar to the report of Ikechebelu and Onwusulu (2007) who found most patients $(77.3 \%)$ presenting with antepartum haemorrhage. This showed that painless vaginal bleeding remains the commonest presentation of placenta praevia. Most of the patients were unbooked $(67.2 \%)$. This was due to the fact that our centre is a referral centre. In lleIfe, Loto and Onile (2008) also discovered that majority of the patients with placenta praevia and having antepartum bleeding were unbooked (58.2\%).

Diagnosis and delivery at term are 38.4 and $45.6 \%$ respectively. In Enugu, Ikechbelu and Onwusulu (2007) discovered a similar trend. The use of conservative management when indicated in our centre apparently increased the percentage of those pregnancies carried to term. Majority of the patient were delivered by Caesarean section $(98.4 \%)$ similar to Ikechbelu and Onwusulu (2007) who reported a Caesarean delivery rate of $90.9 \%$ in their study. Prompt intervention through abdominal delivery in these patient when they presented with marked bleeding or when at term at our center also contributed to the good outcome reported. The commonest type of placenta praevia in the study was type III $(48.8 \%)$ and the same finding was reported by Ikechebelu and Onwusulu (2007). Major placenta praevia (type Ilb-IV) was responsible for $79.2 \%$ of cases as against $72 \%$ reported by Bhat et al. (2004).

More than third (34.6\%) of the babies weighed below $2.5 \mathrm{~kg}$ and the perinatal mortality was 162 per 1,000 births. Ikechebelu and Onwusulu (2007) reported a low birth weight rate weight rate of $27.3 \%$ (Ikechebelu and Onwusulu, 2007) while Loto and Onile (2008) in Ile-Ife reported a perinatal mortality rate of 177 per 1,000 births (Loto and Onile, 2008). Thus low birth weight (predominantly from preterm delivery) and increased perinatal mortality rate are associated with placenta praevia. Ananth et al. (2001) in their study also reported 
Table 2. Antepartum events.

\begin{tabular}{lcc}
\hline Parameters & Number of patients (n = 125) & Percentage \\
\hline Mode of presentation & 115 & \\
Symptomatic & 10 & 92 \\
Asymptomatic & & 8.0 \\
& & \\
Previous uterine surgeries & 50 & 40 \\
Uterine evacuation only & 7 & 5.6 \\
Caesarean section only & 1 & 0.8 \\
Myomectomy only & 5 & 4.0 \\
Caesarean section and uterine evacuation & 62 & 49.6 \\
No prior uterine surgery & & \\
Type of placenta praevia by 36 wks USS & & \\
IA & 5 & 4.0 \\
IB & 4 & 3.2 \\
IIA & 19 & 15.2 \\
IIB & 8 & 6.4 \\
III & 60 & 48.0 \\
IV & 29 & 23.2 \\
& & \\
Type of placenta praevia introperative & & \\
IA & & 4.8 \\
IB & 6 & 2.4 \\
IIA & 3 & 13.6 \\
IIB & 17 & 8.0 \\
III & 10 & 48.8 \\
IV & 61 & 22.4 \\
\hline
\end{tabular}

Table 3. Gestational age at diagnosis and delivery.

\begin{tabular}{lcc}
\hline Parameters & Number of patients $(\mathbf{n}=\mathbf{1 2 5})$ & Percentage \\
\hline Gestational age at diagnosis & & \\
28 - 33 wk 6 days & 33 & 26.4 \\
34 - 36 wk 6 days & 43 & 34.4 \\
37 - 2 wk & 48 & 38.4 \\
$>42$ wk & 1 & 0.8 \\
& & \\
Gestational age at delivery & 13 & 9.6 \\
28 - 33 wk 6 days & 54 & 43.2 \\
$34-36$ wk 6 days & 57 & 45.6 \\
$37-42$ wk & 1 & 1.9 \\
$>42$ wk & & \\
\end{tabular}

that low birth weight and neonatal mortality are more with babies born from pregnancy complicated by placenta praevia.

In this study, $61.6 \%$ of patients were transfused with blood and $78 \%$ of those transfused received two or more units of blood. The ready availability of blood transfusing services at our centre drastically helped to prevent maternal mortality.

In primary postpartum haemorrhage arising from placenta bed, Foley's catheter balloon tamponade may also be considered (Albayrak et al., 2011) in addition to judicious use of oxytocic agents, internal iliac artery ligation and ultimately hysterectomy as last resort (Tower, 2011). 
Table 4. Additional surgical procedures and manoeuvers carried out to control bleeding.

\begin{tabular}{lcc}
\hline Surgical procedures & Number of patients $(\mathbf{n}=\mathbf{1 2 5})$ & Percentage (\%) \\
\hline Simple uterine repair with no additional surgical procedures & 60 & 48 \\
Emergency peripartum subtotal hysterectomy & 12 & 9.6 \\
Uterine artery ligation & 7 & 5.6 \\
Uterine artery ligation followed by subtotal hysterectomy & 8 & 6.4 \\
Under-running stitches to the placenta bed & 35 & 28 \\
Other procedures (e.g. intrauterine catheterization) & 3 & 2.4 \\
\hline
\end{tabular}

Table 5. Maternal and fetal outcome.

\begin{tabular}{|c|c|c|}
\hline Parameters & Number of patients $(n=125)$ & Percentage \\
\hline \multicolumn{3}{|l|}{ Type of gestation } \\
\hline Singleton & 120 & 96.0 \\
\hline Twins & 5 & 4.0 \\
\hline \multicolumn{3}{|l|}{ Mode of delivery } \\
\hline EMLSCS & 89 & 71.2 \\
\hline ELLSCS & 34 & 27.2 \\
\hline SVD & 2 & 1.6 \\
\hline \multicolumn{3}{|l|}{ Fetal outcome } \\
\hline Live births & 109 (including 5set of twins) & 83.8 \\
\hline Stillbirths and ENNDs & 21 & 16.2 \\
\hline \multicolumn{3}{|l|}{ Length of stay } \\
\hline $5-7$ & 72 & 57.6 \\
\hline $8-10$ & 51 & 40.8 \\
\hline$>10$ & 2 & 1.6 \\
\hline \multicolumn{3}{|l|}{ Foetal births weights } \\
\hline $1.5-1.9$ & 12 & 9.2 \\
\hline $2.0-2.4$ & 33 & 25.4 \\
\hline $2.5-2.9$ & 39 & 30.0 \\
\hline 3.0-3.4 & 24 & 18.4 \\
\hline 3.5-3.9 & 11 & 8.5 \\
\hline 4 and above & 3 & 2.3 \\
\hline Not recorded & 8 & 6.2 \\
\hline
\end{tabular}

However, pelvic arterial catheterization and embolization have proven to be safe and effective in intractable postpartum haemorrhage and this might eliminate the need for hysterectomy, thus preserving the woman's reproductive potential (Jang et al., 2011).

Only two women stayed more than 10 days on admission after delivery. No maternal mortality was reported during the study period. This was as a result of the good obstetric care provided at our centre. It supported the fact that mortality rate from placenta praevia can be greatly reduced if ideal care is given (Jennifer and Uzelac, 2007).

\section{Limitation}

The study is hospital based and may not reflect the finding in the community; this is a review and not a case controlled study.

Poor record keeping was also a limitation as the birth weight of some of the babies were not documented.

\section{CONCLUSION}

Antepartum haemorrhage is the commonest mode of 
presentation of placenta praevia which contributes significantly to poor perinatal as well as maternal outcome. An improvement in antenatal care delivery in the country's health care delivery system so that all pregnant women with placenta praevia are identified early and without delay attended to at secondary and tertiary centres will result in very low maternal and fetal complications.

Enlightenment campaigns of the general public on the need for voluntary blood donation should be embarked upon, and medical personnel should be regularly trained on the management of obstetric haemorrhage.

\section{REFERENCES}

Albayrak M, Ozdemir I, Koc O, Damiraran Y, 2011. Postpartum haemorrhage from the lower uterine segment secondary to placenta praevia and acceta; successful conservative management with Foley's balloon temponade. Aust N ZJ Obstet Gynaecol, 51(14): $377-$ 380.

Ananth CV, Demissie K, Smuilan JC, Vintzileos AM, 2001. Relationship among placenta placenta praevia, fetal growth restriction and preterm delivery; a population based study. Obstet Gynecol, 98(2): 299-306.

Ananth CV, Smulian JC, Vintzileos AM, 2003. The effect of placenta praevia on neonatal mortality; a population based in the United States, 1989 through 1997. Am J Obstet Gynecol, 188(5): 12991304.

Bendetti TJ, 2002. Obstetric haemorrhage. In: Gabbe S. G., Niebyl J. R., Simpson J. Livingstone, 516-521.

Bhat SM, Hamdi IM, Bhat SK, 2004. Placenta praevia in a referral hospital in Oman. Saud Med J, 25(6): 728-731.

Calleja-Aguis J, Custo R, Brincat M, Calleja N, 2006. Placenta abruption and placenta praevia. Eur Clin Obstetr Gynaecol, 2: 121127.

Cieminski A, Dlugolecki F, 2005. Relationship between placenta praevia and material age, parity and prior Caesarean deliveries. Ginekol Pol, 76(4): 284-289.

Clarke SL, Koonings PP, Phelan JP, 1985. Placenta praevia/accreta and previous Caesarean section. Obstetr Gynaecol; 66: 89.

Cunningham FG, Gant NF, Leveno KJ, Gilstrap III LC, Hauth JC, Wenstrom KD, 2001. Obstetric Haemorrhage. In William's Obstetrics. $21^{\text {st }}$ ed. McEraw - Hill companies inc: 29.

Eniola AO, Bako AU, Selo-Ojeme DO, 2002. Risk factors for placenta praevia in southern Nigeria. East Afr J, 79(10): 5350-5358.

Fishman SG, Chasnen ST, Maheshwari B, 2011. Risk factors for preterm delivery in women with placenta praevia. J Perinat Med, 40(1): 39-42.

Fishman SG, Chasen ST, 2011. Risk factors for emergent preterm delivery in women with placenta praevia and ultrasound findings suspicious for placenta accreta. J Perinat Med, 39(6): 693-696.

Gurol-Uganzi I, Cromwell DA, Edozien LC, Smith GCS, Onwere C, Mahmood TA, Templeton A, van der Meulen JH, 2011. Risk of placenta praevia in second birth after first birth Caesarean section: a population based study and meta-analysis. BMC Pregnancy Childbirth, 11: 95.

Hanretty KP, 2003. Vaginal bleeding in pregnancy. Illustrated Obstetries. $6^{\text {th }}$ ed. Churchill Livingstone. pp. 187.

Ikechebelu JI, Onwusulu DN, 2007. Placenta praevia: review of clinical presentation and management in a Nigerian Teaching Hospital. Niger J Med; 16(1): 61-64.

Jang DG, Jo YS, Lee GS, 2011. Risk factors for neonatal in placenta praevia. Int J Med Sci, 8(7): 554-557.

Jennifer S, Uzelac PS, 2007. Third trimester vaginal bleeding. In: Decherney A.H., Nathan L., Godwin T.M., Laufer N. (eds). Current Diagnosis and Treatment; Obstetrics and Gynecology. $10^{\text {th }}$ ed. Mcgraw Hill, New York. 336-339.
Kiay HH, 2003. Placenta and abruption. In; Scott J.R., Gibbs R.S Karlan B.Y., Haney A.F., Danforth D.N., (eds). Danforth's Obstetrics and Gynaecology. $9^{\text {th }}$ ed. Lippincott Williams and Wilkians publishers, 26.

Kwawukume EY, 2002. Antepartum haemorrhage. In: Kwawume E.Y., Emuvyan Ltd. Accra, Ghana. 140-150.

Lavery SP, 1990. Placenta praevia. Clin Obstetr Gynaecol, 33: 414.

Loto $O$, Onile TG, 2008. Placenta praevia at Obafemi Awolowo University Teaching Hospital Complex, Ile-Ife: A ten year analysis. Niger J Clin Pract, 11(2): 130-133.

MacAfee CHG, 1945. Placenta praevia: A study of 174 cases. J Obstet Gynaecol Brit Emp, 52:313-324.

Nelson JP, 1995. Antepartum Haemorrhage. In: Dewhurst Textbook of Obstetrics and Gynaecology for Postgraduates. 5th Ed. Edmonds K. Ed. Blackwell Scientific Publications, Oxford. pp. 164-174.

Nyago DD, Muithir JT, Kigbu JH, 2010. Risk factor for placenta praevia in Jos, North central Nigeria. Niger J Med, 19(1): 46-49.

Omu AE, 2004. Antepartum haemorrhage. Placenta praevia in: Okpere E., (ed). Clinical Obstetrics. Revised ed. Uniben Press, Benin City; 158-61.

Rosenberg T, Pariente G, Sergienko R, Wiznitzer A, Sheiner E, 2011. Critical analysis of risk factor and outcome of placenta praevia. Arch Gynecol Obstet, 284(1): 47-51.

Sheiner E, Shoham-vardi I, Hallak M, Hershowitz R, Katz M, Mazor M, 2001. Placenta praevia: obstetric risk factors and pregnancy outcome. J Matern Fetal Med, 10(6): 414-419.

Tower C. 2011. Obstetric emergencies. In: Baker., Kenny L.C., (eds). Obstetrics by ten teachers. $19^{\text {th }}$ ed. Bookpower, London. pp: 245-249.

Citation: Olugbenga EO, Eifediyi RA, Olugbenga MA, Ikheloa J, Okoeguale J, Omoregbee $\mathrm{HI}$ and Oboh SA, 2019. Placenta praevia with or without antepartum bleeding in a Nigerian suburban tertiary health institution. Int Res J Med Med Sci, 7(2): 53-59. 